\title{
Phospholipid transfer protein activity in two cholestatic patients
}

\author{
Departments of Internal Medicine and Clinical Pathology, Lipids \\ Laboratory and Experimental Medicine and Surgery Center, \\ Faculdade de Ciências Médicas, Universidade Estadual de Campinas, \\ Campinas, São Paulo, Brazil
}

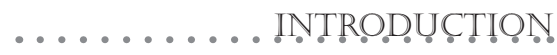

Plasma phospholipid transfer protein mediates the transfer of phospholipids from triglyceride-rich lipoproteins, very low density lipoproteins and low density lipoproteins to high density lipoproteins, a process that is also efficient between high density lipoprotein particles. It promotes a net movement of phospholipids, thereby generating small lipid-poor apolipoprotein AI that contains particles and subfractions that are good acceptors for cell cholesterol efflux. We measured the activity of plasma phospholipid transfer protein in two cholestatic patients, assuming that changes in activity would occur in serum that was positive for lipoprotein $\mathrm{X}$.

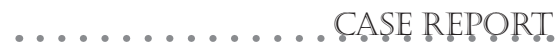

Patient 1 was a 58-year-old man who presented primary sclerosing cholangitis shown by retrograde endoscopic cholangiopancreatography and ulcerative colitis shown by colonoscopy. A liver biopsy revealed moderately active disease of the biliary tract. He was released from hospital under cholestyramine treatment. The results of serum electrophoresis are shown in Figure 1 (panels A and C).

Patient 2 was a 40-year-old woman. Liver biopsy revealed the presence of antimitochondrion antibodies consistent with a diagnosis of primary biliary cirrhosis. She was submitted to cholestyramine and fat-soluble vitamin supplementation. No established atherosclerotic disease was detected in either patient, as often found. ${ }^{1}$
Both patients presented severe increases in the levels of bilirubin, hepatic and biliary enzymes (not shown). In Table 1, the changes in the lipid parameters and the phospholipid transfer protein activity are shown.

In Figure 1, the lipoprotein electrophoresis (Beckman Paragon) confirmed the presence of lipoprotein $\mathrm{X}$ in both patients (panels A and B), revealed by a fraction that is more cathodic than low density lipoprotein, located near the origin. Alkaline phosphatase isoenzyme electrophoresis (panels C and D) showed a band that was suggestive of an association between biliary alkaline phosphatase and lipoprotein X.

............. DISCGUSSIOG

Xanthomas and markedly raised plasma cholesterol levels coexist in chronic liver disease in the presence of lipoprotein X. ${ }^{1}$ Lipoprotein $\mathrm{X}$ is not taken up by the liver lipoprotein receptors (B, E and low density lipoprotein receptor related protein) and therefore can not exert a feedback control on hepatic cholesterol biosynthesis. It is removed from the circulation by the reticuloendothelial system.

The reduction in the activity of phospholipid transfer protein in these patients was probably due to changes in the chemical composition of the lipoproteins, such as phospholipid enrichment, especially in relation to high density lipoprotein. ${ }^{2,3}$ In addition to this, lipoprotein $\mathrm{X}$, which is also rich in phospholipids, could compete with high density lipoprotein as a substrate for phospholipid transfer protein. The reduced
- Eliana Cotta de Faria

- Adriana Celeste Gebrin

- Wilson Nadruz Júnior

- Lucia Nassi Castilho

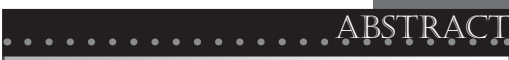

CONTEXT: Plasma phospholipid transfer protein mediates the transfer of phospholipids from triglyceride-rich lipoproteins, very low density lipoproteins and low density lipoproteins to high density lipoproteins, a process that is also efficient between high density lipoprotein particles. It promotes a net movement of phospholipids, thereby generating small lipid-poor apolipoprotein Al that contains particles and subfractions that are good acceptors for cell cholesterol efflux.
\end{abstract}

CASE REPORT: We measured the activity of plasma phospholipid transfer protein in two cholestatic patients, assuming that changes in activity would occur in serum that was positive for lipoprotein $X$. Both patients presented severe hypercholesterolemia, high levels of low density lipoprotein cholesterol and, in one case, low levels of high density lipoprotein cholesterol and high levels of phospholipid serum. The phospholipid transfer activity was close to the lower limit of the reference interval.

To our knowledge, this is the first time such results have been presented. We propose that phospholipid transfer protein activity becomes reduced under cholestasis conditions because of changes in the chemical composition of high density lipoproteins, such as an increase in phospholipids content. Also, lipoprotein X, which is rich in phospholipids, could compete with high density lipoproteins as a substrate for phospholipid transfer protein

KEY WORDS: Cholestasis. Lipoprotein X. Phospholipids. Apolipoprotein A-I. Hypercholesterolemia. 


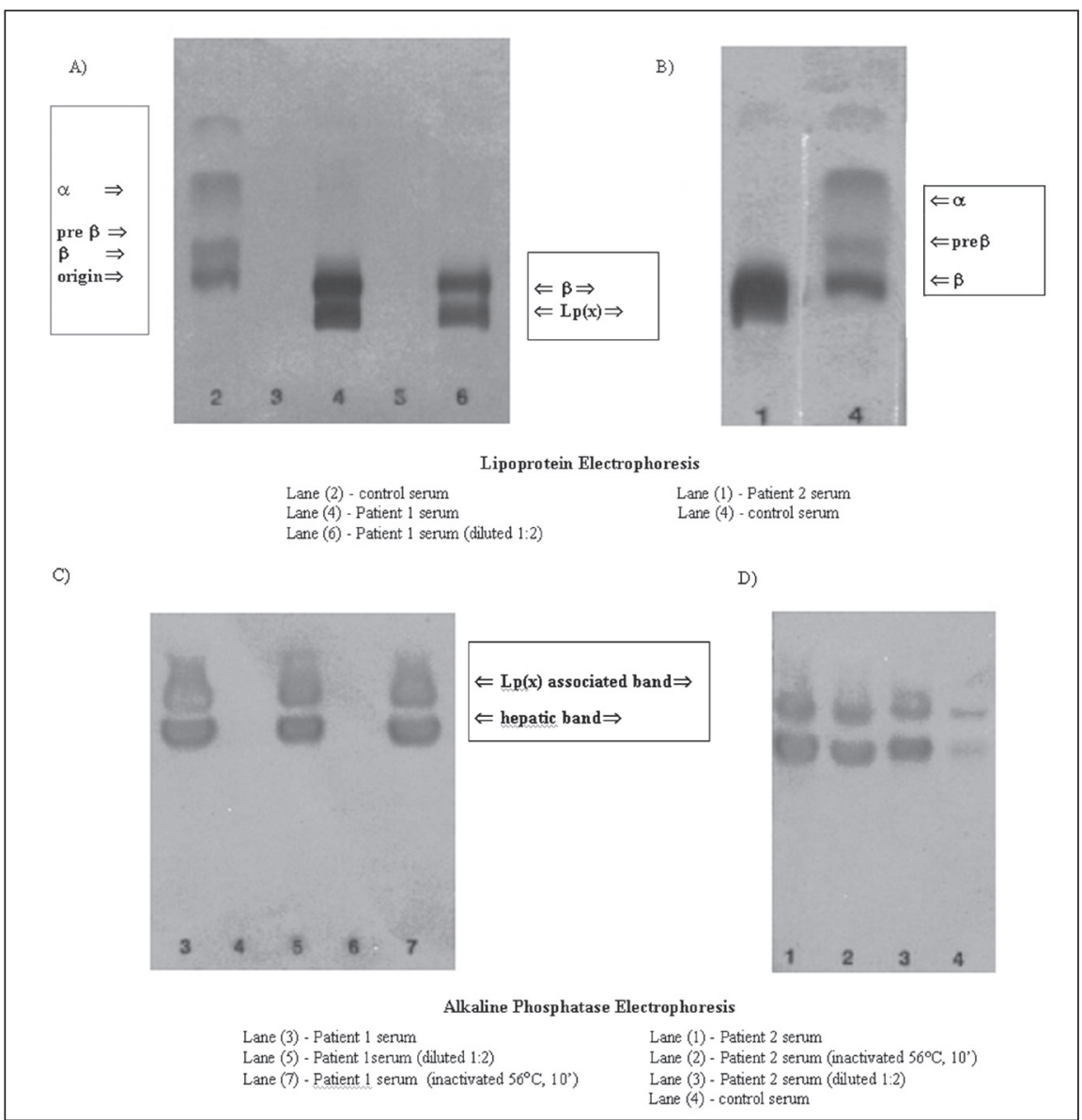

phospholipid transfer protein activity shown here could also explain the low levels of high density lipoprotein cholesterol found in one of these patients.

We suggest that studies of lipoprotein metabolism in such patients are extremely important because they might further increase our knowledge of the underlying mechanisms involved in dyslipidemia and the absence of atherosclerosis in the presence of lipoprotein $\mathrm{X}^{4}$

1. Crippin JS, Lindor KD, Jorgensen R, et al. Hypercholesterolemi and atherosclerosis in primary biliary cirrhosis: what is the risk? Hepatology. 1992;15(5):858-62.

2. Wolfbauer G, Albers JJ, Oram JF. Phospholipid transfer protein enhances removal of cellular cholesterol and phospholipids by high-density lipoprotein apolipoproteins. Biochim Biophys Acta. 1999;1439(1):65-76

3. Huuskonen J, Ehnholm C. Phospholipid transfer protein in lipid metabolism. Curr Opin Lipidol. 2000;11(3):285-9.

4. van Haperen R, van Tol A, Vermeulen P, et al. Human plasma phospholipid transfer protein increases the antiatherogenic potential of high density lipoproteins in transgenic mice. Arterioscler Thromb Vasc Biol. 2000;20(4):1082-8.

Figure 1. Serum lipoprotein and alkaline phosphatase electrophoresis (agarose gel).

Table 1. Serum lipids, lipoproteins, apolipoproteins $(\mathrm{mg} / \mathrm{dl})$ and phospholipid transfer protein activity (\% phospholipid transfer/hour) in two cholestatic patients

\begin{tabular}{|c|c|c|c|c|c|c|c|c|}
\hline Patients & Cholesterol* & Triglycerides* & $\begin{array}{c}\text { Low } \\
\text { density } \\
\text { lipoprotein } \\
\text { cholesterol* }\end{array}$ & $\begin{array}{c}\text { High } \\
\text { density } \\
\text { lipoprotein } \\
\text { cholesterol* }^{*}\end{array}$ & Phospholipids † & $\begin{array}{c}\text { Phospholipid transfer } \\
\text { protein activity } ¥\end{array}$ & $\begin{array}{l}\text { Apolipoprotein } \\
\text { AI § }\end{array}$ & $\begin{array}{c}\text { Apolipoprotein } \\
\text { B II }\end{array}$ \\
\hline 1 & 995 & 187 & 943 & 22 & 1156 & undetectable & 57 & 170 \\
\hline 2 & 731 & 244 & 675 & 49 & 640 & 2 & $<25$ & 231 \\
\hline
\end{tabular}

transfer/hour, with reference interval values taken from a healthy control population, $n=47 ;(\xi)$ reference range $=94$ to $199 \mathrm{mg} / \mathrm{dl}$; $(\|)$ ) reference range $=40$ to $109 \mathrm{mg} / \mathrm{dl}$. 


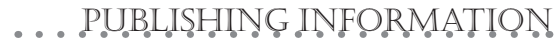

Eliana Cotta de Faria, MD, PhD. Department of Clinical Pathology, Lipids Laboratory and Experimental Medicine and Surgery Center, Faculdade de Ciências Médicas, Universidade Estadual de Campinas, Campinas, São Paulo, Brazil.

Adriana Celeste Gebrin, MD. Lipids Laboratory and Experimental Medicine and Surgery Center, Faculdade de Ciências Médicas, Universidade Estadual de Campinas, Campinas, São Paulo, Brazil.

Wilson Nadruz Júnior, MD. Department of Internal Medicine, Lipids Laboratory and Experimental Medicine and Surgery Center, Faculdade de Ciências Médicas, Universidade Estadual de Campinas, Campinas, São Paulo, Brazil.

Lucia Nassi Castilho, PhD. Department of Clinical Pathology, Lipids Laboratory and Experimental Medicine and Surgery Center, Faculdade de Ciências Médicas, Universidade Estadual de Campinas, Campinas, São Paulo, Brazil.

Sources of funding: Faep (Fundação de Apoio ao Ensino e Pesquisa) - grant no 0283/96.

\section{Conflict of interest: None}

Date of first submission: May 16, 2003

Last received: September 17, 2003

Accepted: November 13, 2003

\section{Address for correspondence:}

Eliana Cotta de Faria

Departamento de Patologia Clínica - Faculdade de Ciências Médicas da Universidade de Campinas (FCM/Unicamp)

R. Tessália Vieira de Camargo, 126

Barão Geraldo

Campinas (SP) - Brasil - CEP 13084-971

Tel. (+55 19) 3788-9452

Fax (+55 19) 3788-9434

E-mail: cotta@fcm.unicamp.br

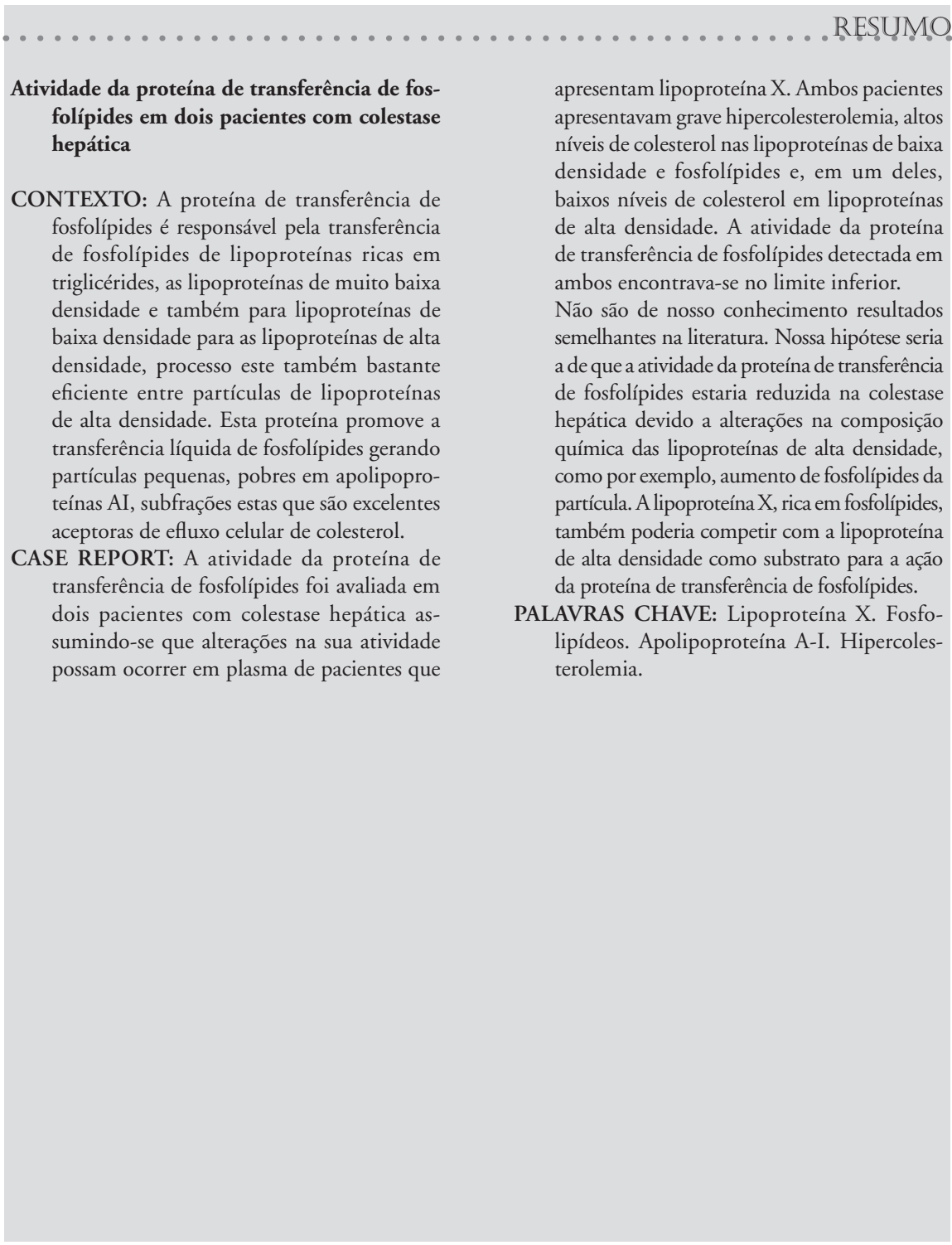

